\title{
A psychophysiology-based driver model for the design of driving assistance systems
}

\section{Franck MARS}

PsyCoTec team
Philippe CHEVREL

Control team

Institut de Recherche en Communications

et Cybernétique de Nantes 


\section{The problem}

Lane departure crashes may be due to several causes:

- steering errors

- driver distraction

Countermeasures: advanced driving assistance systems (ADAS)

- lane departure warning systems

- lane keeping systems

- driver state monitoring

For all types of ADAS:

- a key problem: to predict the driver behaviour

- our approach: to incorporate a driver model in the design process 


\section{Step 1: \\ Building a visuomotor model of steering control}




\section{What we need}

\section{A model of steering control}
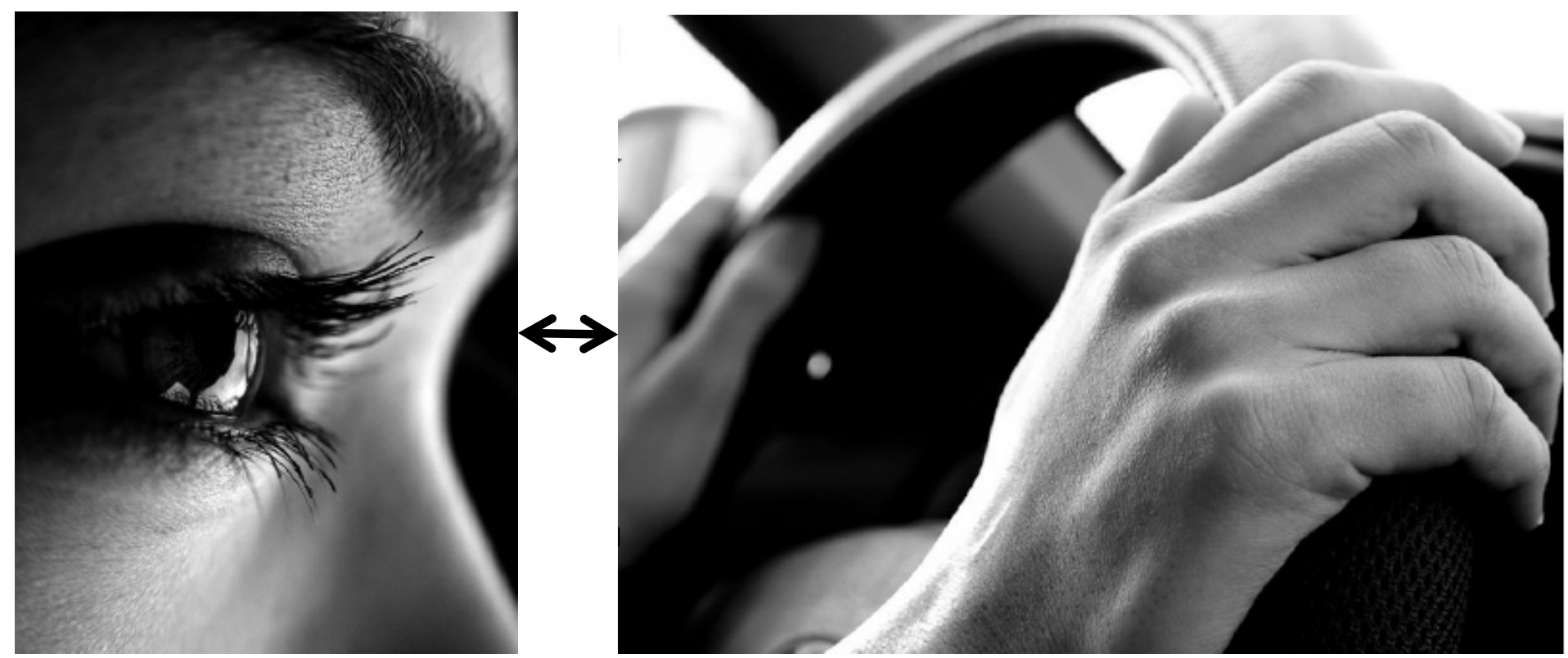

- A model that processes information from the visual scene

- A motor system that converts steering intention into actions 


\section{Two-levels visual control of steering}

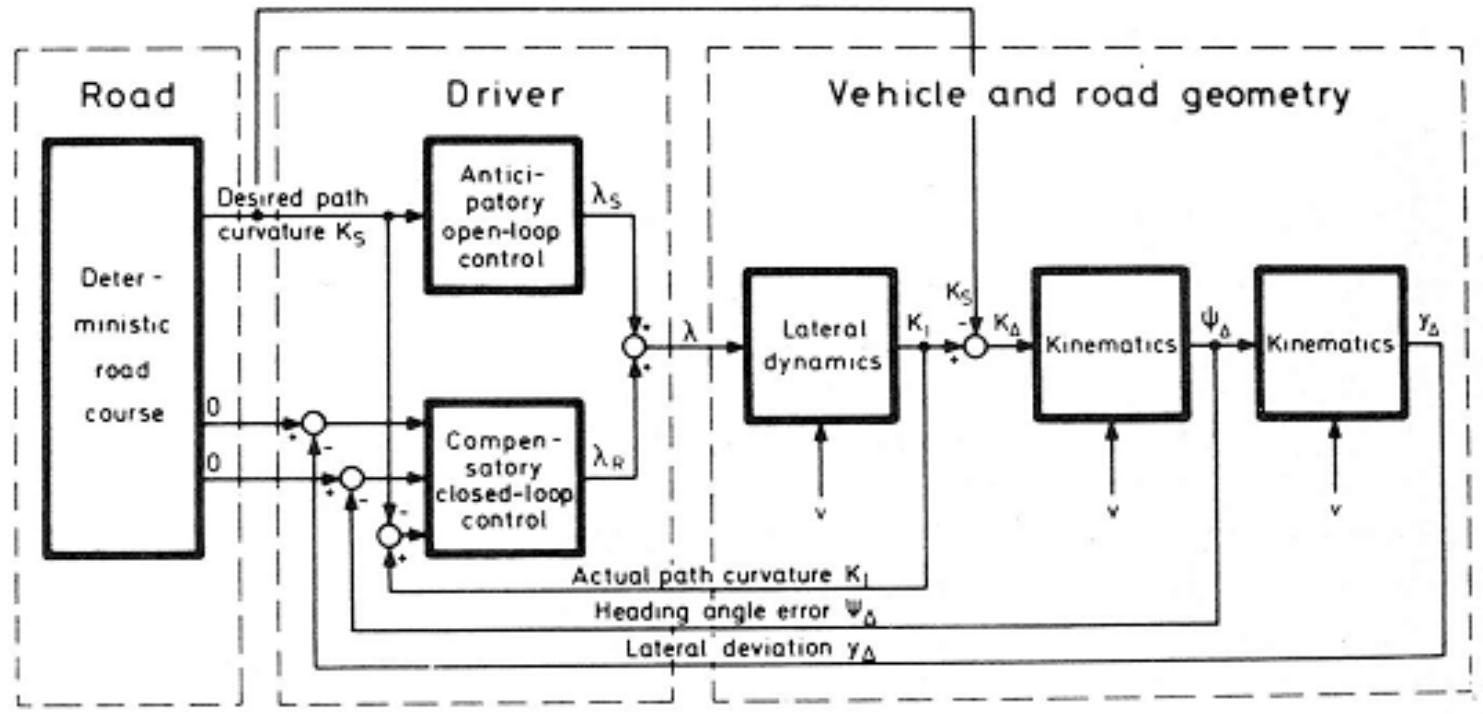

Donges (1978), Human Factors

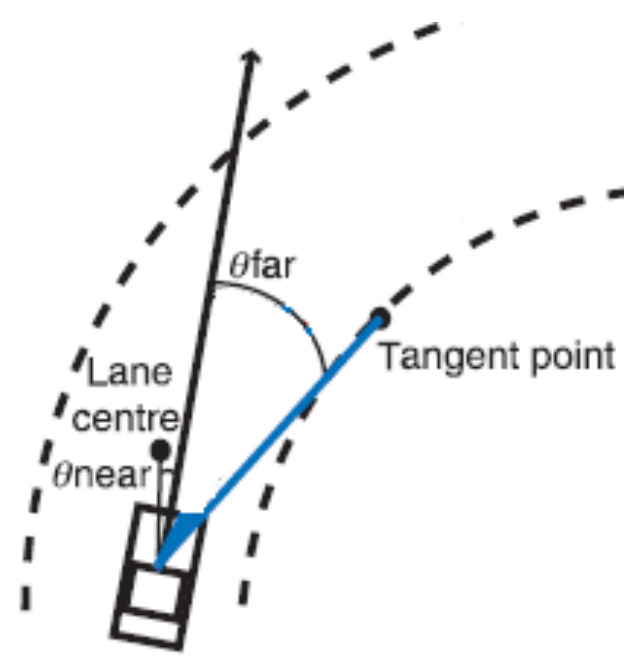

\section{Anticipatory control}

- anticipation of changes in road curvature

- fed by far visual information: $\theta$ far (tangent point)

\section{Compensatory control}

- on-line correction of lateral position errors

- fed by near visual information: $\theta$ near (lane center) 


\section{Adding a motor system}
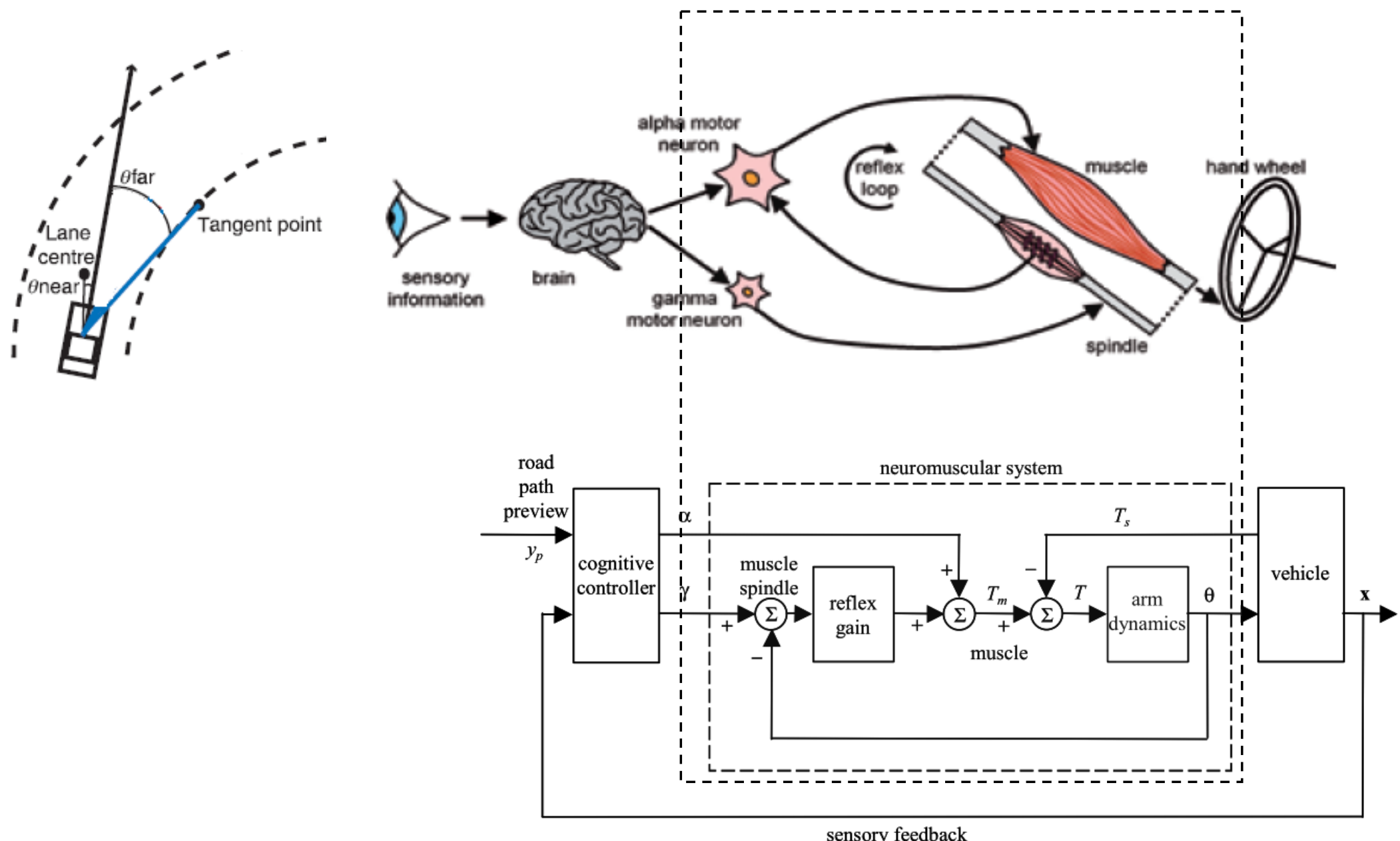

Hoult \& Cole (2008), Vehicle Systems Dynamics 


\section{Our driver model}

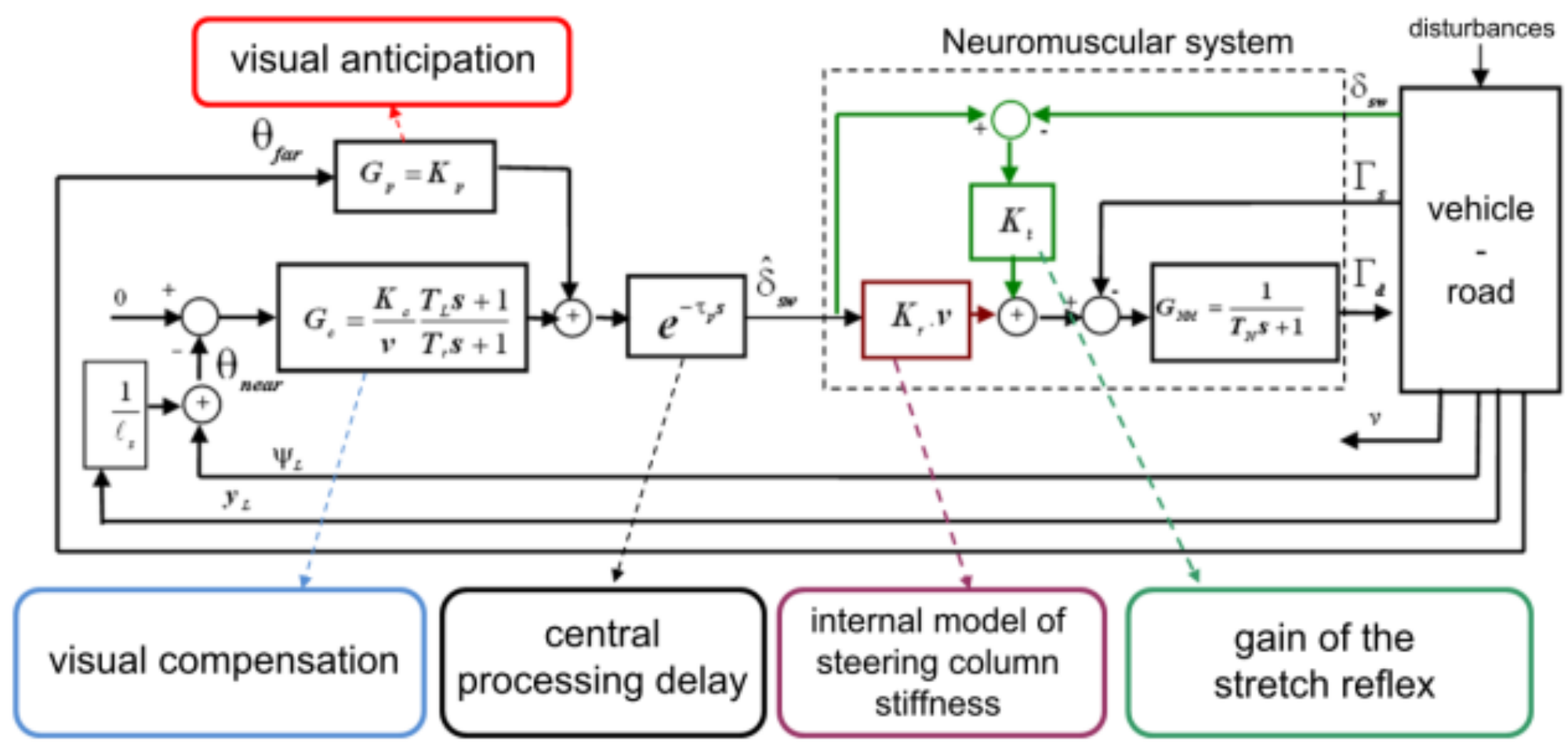

Saleh et al. (2011) IFAC World ; Mars et al (2011), HFES

\section{A cybernetic model:}

- designed as a function of current knowledge on perceptual and motor processes

- that can be identified in various driving situations 


\section{Step 2: \\ Application to haptic shared control}




\section{Shared control without a driver model}

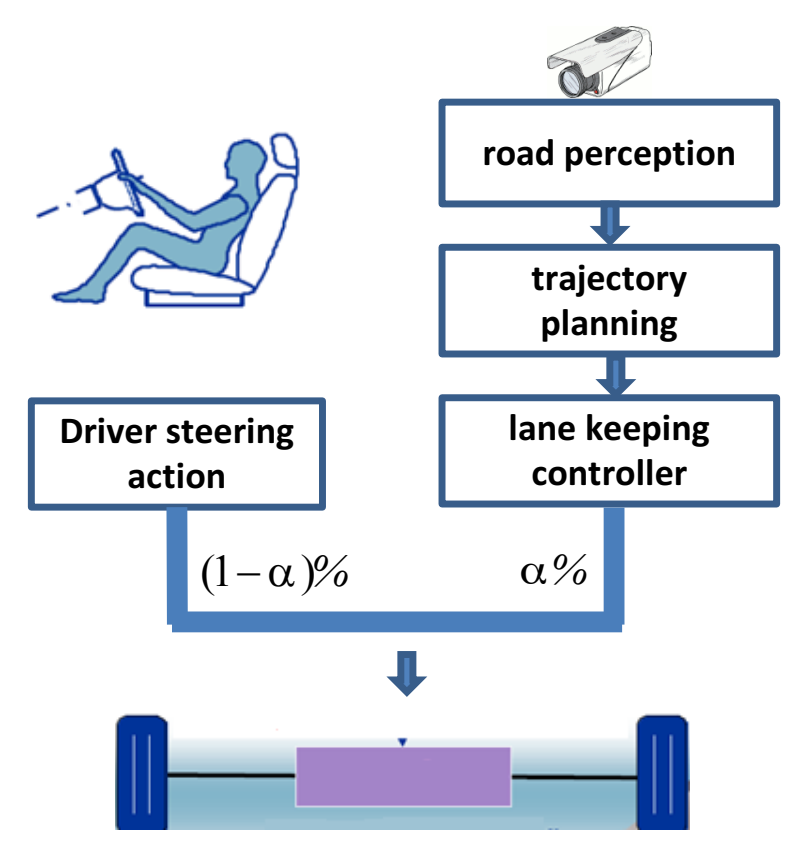

\section{Haptic shared control:}

continuous and simultaneous action of the driver and an automaton on the steering wheel

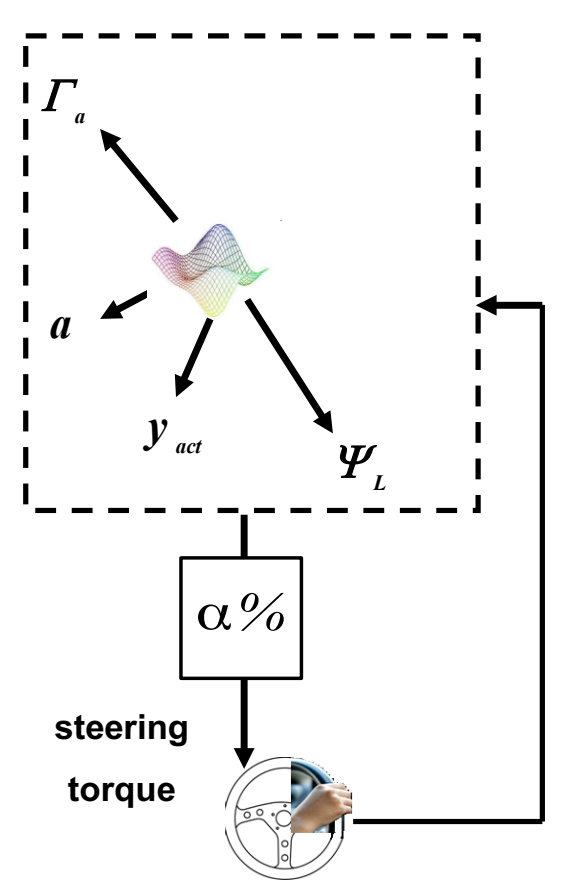

Without a driver model:

- the controller optimizes performance and safety criteria

- no prediction of the driver behavior 
 \\ Shared control with a driver model}

\section{road curvature}
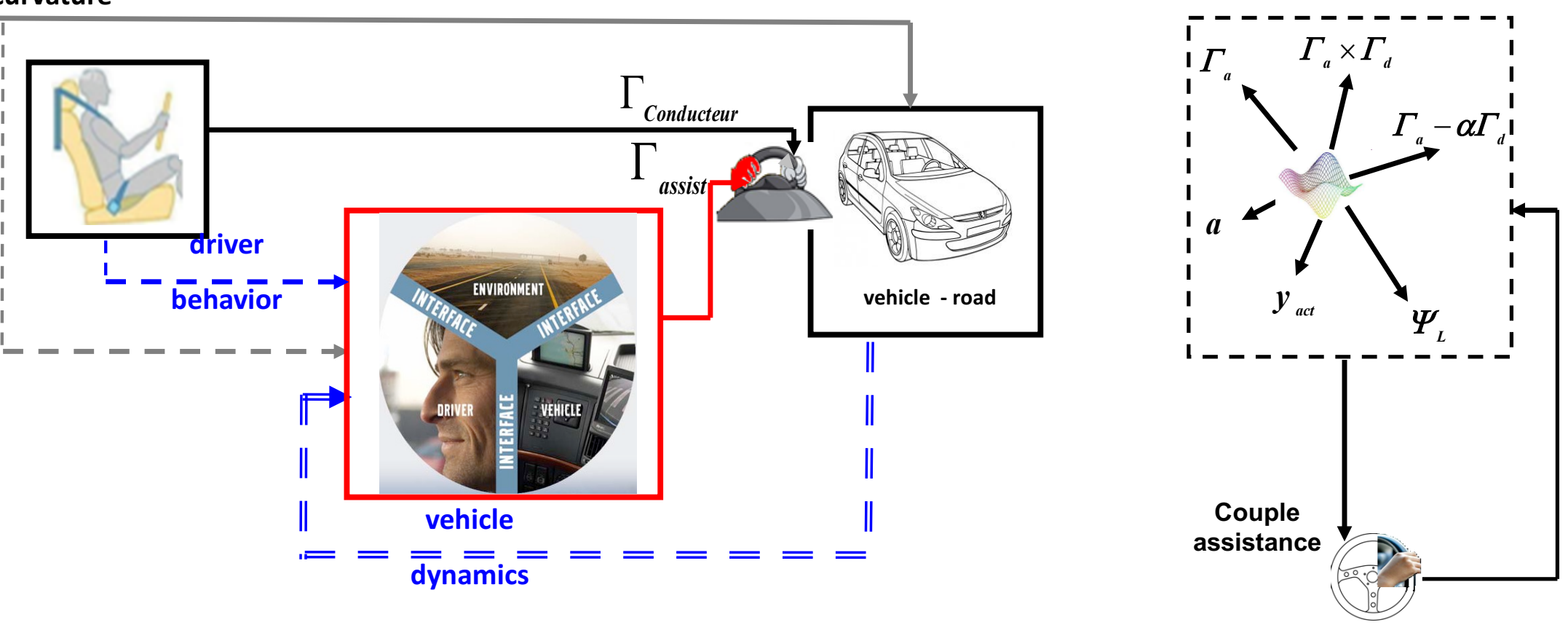

With a driver model, the control law also optimizes cooperation criteria

- shared control is smoother

- improved agreement between the driver and the automation 


\section{Step 3: \\ Application to distraction state estimation}




\section{A steering model for distraction}

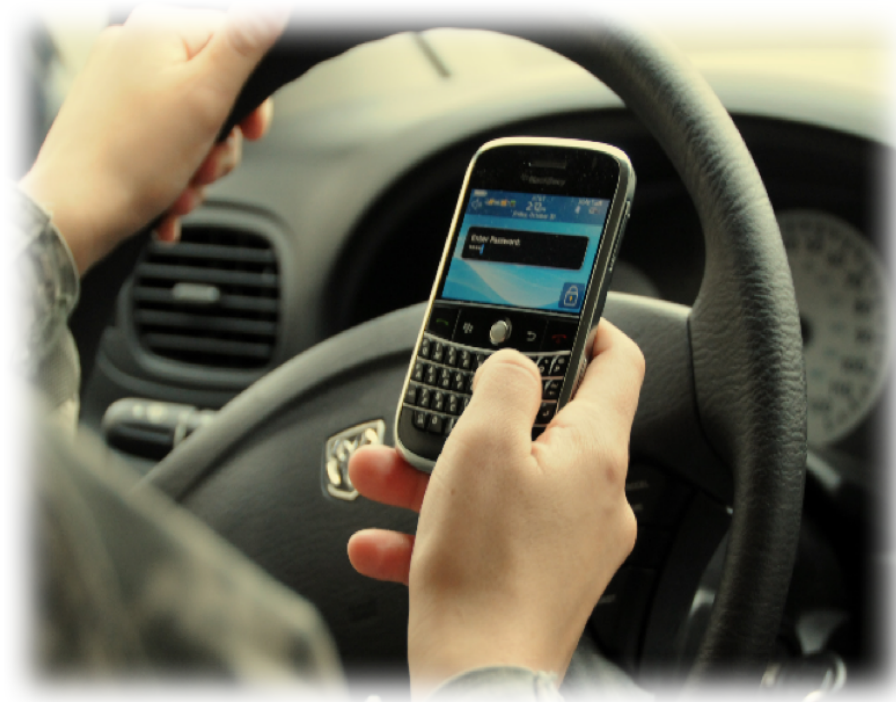

Different types of distraction influence steering in differents ways

- cognitive distraction

- visual distraction

- motor distraction

- visuomotor distraction

Can a visuomotor model help detect and discriminate distraction episodes?

Discriminating distraction types by means of on-line parameter identification

$>$ the visual anticipation gain decreases only for high visual distraction

$>$ motor distraction influences neuromuscular dynamics only

$>$ visual distraction propagates to the motor system parameters 


\section{Want more details?}

\section{When the driver model drives}

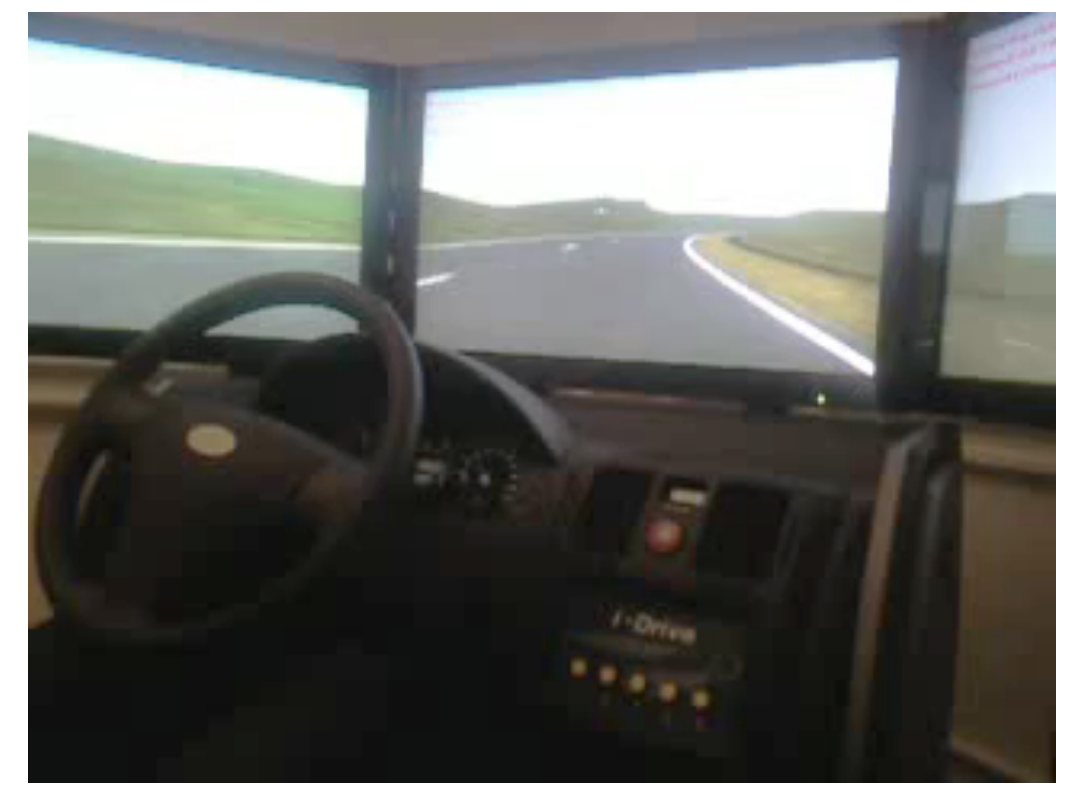

Contact information

franck.mars@irccyn.ec-nantes.fr

\section{Presentation of the model}

- Mars, F., Saleh, L., Chevrel, P., Claveau, F., \& Lafay, J.F. (2011). Modeling the visual and motor control of steering with an eye to shared-control automation. Proceedings of the Human Factors and Ergonomics Society 55th Annual Meeting, pp. 1422-1426

- Saleh, L., Chevrel, P., Mars, F., Lafay, J.F., \& Claveau, F. (2011). Humanlike cybernetic driver model for lane keeping. Proceedings of the 18th IFAC World Congress, pp. 4368-4373

\section{Application to haptic shared control}

- Saleh, L., Chevrel, P., Claveau, F., Lafay, J.F. \& Mars, F. (2013). Shared steering control between a driver and an automation: Stability in presence of driver model uncertainty. IEEE Transactions on Intelligent Transportation Systems, 14(2), 974-983

\section{Application to driver distraction}

- Ameyoe, A., Chevrel, P., Le Carpentier, E., Mars, F. \& Illy, H. (2015). Identification of a Linear Parameter Varying Driver Model for the Detection of Distraction. IFAC-PapersOnLine, 48(26), pp. 37-42

- Ameyoe, A., Mars, F., Chevrel, P., Le Carpentier, E. \& Illy, H. (2015). Estimation of driver distraction using the prediction error of a cybernetic driver model. Proceedings of the Driving Simulation Conference Europe 2015, pp. 13-18 